\title{
PENGARUH INFLASI TERHADAP INDEKS PEMBANGUNAN MANUSIA (IPM) DI INDONESIA
}

\author{
Indah Pangesti ${ }^{1}$; Rudy Susanto ${ }^{2}$ \\ ${ }^{1}$ Dosen Universitas Indraprasta PGRI Program Studi Pendidikan Bahasa Inggris (FBS); \\ ${ }^{2}$ Dosen Universitas Indraprasta PGRI, Program Studi Pendidikan Ekonomi (FIPPS) \\ E-mail: esthicute@gmail.com; rudy.susanto19@gmail.com
}

\begin{abstract}
This study aims to determine and analyze the effect of inflation levels to ward Human Development Index (HDI) in Indonesia, and the magnitude of the elasticity of the level of Human Development Index (HDI) in Indonesia. The method used is quantitative descriptive using secondary data from the Central Bureau of Statistics from the years 2000-2015. Methods of data analysis used correlation analysis, determination analysis, simple linear regression analysis, t-test, and test of elasticity. The results showed: there is a negative relationship between inflation and the human development index (HDI) in the category of moderately correlation coefficient of -0.42 and the contributions made by the inflation of the human development index (HDI) of $17.64 \%$; if inflation rose by $1 \%$, the human development index (HDI) will decrease by $0.36 \%$ with a constant value of 73.33 ; inflation have not a significant effect on the human development index (HDI) and its elasticity is not eslatis (inelastic).
\end{abstract}

Keywords : Inflation, Human Development Index.

\begin{abstract}
ABSTRAK
Penelitian ini bertujuan untuk mengetahui dan menganalisis pengaruh tingkat inflasi terhadap tingkat Indeks Pembangunan Manusia (IPM) di Indonesia, dan besarnya elastisitas terhadap tingkat Indeks Pembangunan Manusia (IPM) di Indonesia. Metode penelitian yang digunakan adalah deskriptif kuantitatif dengan menggunakan data sekunder dari Badan Pusat Statistik dari tahun 2000-2015. Metode analisis data yang digunakan analisis korelasi, analisis determinasi, analisis regresi linear sederhana, uji t-test, dan uji elastisitas. Hasil penelitian menunjukan : terdapat hubungan yang negatif antara inflasi dengan indeks pembangunan manusia (IPM) dengan katagori sedang dengan nilai koefisien korelasi sebesar -0,42 dan kontribusi yang diberikan oleh inflasi terhadap indeks pembangunan manusia (IPM) sebesar $17,64 \%$; apabila inflasi naik $1 \%$ maka indeks pembangunan manusia (IPM) akan turun sebesar $0,36 \%$ dengan nilai konstanta sebesar 73,33 ; inflasi tidak mempunyai pengaruh yang signifikan terhadap indeks pembangunan manusia (IPM) dan elastisitasnya tidak eslatis (inelastis).
\end{abstract}

Kata Kunci : Inflasi, Indeks Pembangunan Manusia. 


\section{A. PENDAHULUAN}

Inflasi adalah kenaikan harga barang kebutuhan pokok rumah tangga secara terus menerus. Data kenaikan harga-harga kebutuhan pokok ini dicatat oleh Badan Pusat Statistik (BPS) yang kantor-kantor cabangnya ada di daerah provinsi sampai ke kecamatan. Indikator inflasi ini dibuat oleh para ahli yang disebut dengan Indeks Harga Konsumen (IHK).

Secara historis inflasi Indonesia lebih tinggi dibandingkan dengan negaranegara berkembang lainnya, seperti Thailand, Malaysia, dan sebagainya. Negaranegara ASEAN mengalami inflasi antara 3\% sampai 5\% pada periode tahun 20052014. Sedangkan Indonesia tingkat rata-rata inflasi setahun sebesar 8,5\% dalam periode yang sama. (BPS, 2015). Mengapa demikian? Salah satu sebabnya adalah Indonesia mengimpor bahan bakar minyak, sehingga harga bahan bakar naik dan tidak lagi disubsidi oleh pemerintah. Harga bahan bakar yang naik ini menyebabkan biaya transportasi naik (seperti : angkot, bis, taxi, dan transportasi lainnya). Akibat menaiknya biaya transportasi maka harga sayur mayur, harga daging sapi, ayam mengalami kenaikan.

Karena inflasi meningkat, maka tingkat kesejahteraan menjadi terganggu, yakni daya beli masyarakat menurun. Kesejahteraan masyarakat ini diukur dengan indeks kesejahteraan rakyat yang dinyatakan dengan Indeks Pembangunan Manusia (IPM) atau Human Development Index (HDI).

Indeks Pembangunan Manusia (IPM) merupakan jumlah komposit indikator pendidikan, kesehatan, dan ekonomi. (Todaro, 2003). Indeks Pembangunan Manusia (IPM) ini yang dinyatakan dapat dianggap sebagai Indeks Kesejahteraan Manusia. Siapa yang menghitung ini ? Jawabannya adalah Badan Pusat Statistik (BPS). Data mengenai Indeks Pembangunan Manusia (IPM) ini setiap tahun ada di Badan Pusat Statistik (BPS). Setiap negara mempunyai data seperti untuk keperluan mereka sendiri. Keperluan itu antara lain untuk analisis kebijakan, untuk penelitian ilmu pengetahuan yang dilakukan oleh dosen atau pengajar, para peneliti, pengusaha, dan lain sebagainya. Adapun tujuan dari penelitian ini adalah; 1) Untuk mengetahui dan menganalisis pengaruh tingkat inflasi terhadap tingkat Indeks Pembangunan Manusia (IPM) di Indonesia, 2)Untuk mengetahui dan menganalisis besarnya elastisitas inflasi terhadap tingkat Indeks Pembangunan Manusia (IPM) di Indonesia.

\section{B. KAJIAN PUSTAKA}

\section{Inflasi}

Inflasi adalah suatu keadaan dimana tingkat harga secara umum (price level) cenderung meningkat.

Penyebab inflasi itu adalah kenaikan permintaan melebihi penawaran atau di atas kemampuan berproduksi. Jika ini yang terjadi, inflasi ini disebut datang dari sisi permintaan (demand pull inflation). Inflasi juga dapat terjadi atau datang dari sisi penawaran, yakni kenaikan biaya produksi sehingga harga naik. Jika ini yang terjadi maka inflasi ini disebut cost push inflation. (Sukirno, 2006)

Inflasi dapat juga terjadi jika jumlah uang yang beredar di masyarakat meningkat. Jika jumlah uang naik, sedangkan jumlah barang tetap, maka harga- 
harga barang akan meningkat.

Di Indonesia inflasi dari tahun 2000-2015 jika dilihat dari data Badan Pusat Statistik (BPS) rata-rata dalam kurun waktu 2010-2015 dapat dikendalikan pemerintah, yakni di bawah $10 \%$ per tahun. (BPS, 2015). Tolok ukur inflasi diukur dengan Indeks Harga Konsumen (IHK) yang terdiri atas 7 (tujuh) kelompok, yakni :

a) Kelompok Bahan Makanan.

b) Kelompok Makanan Jadi, Minuman, dan Tembakau.

c) Kelompok Perumahan.

d) Kelompok Sandang.

e) Kelompok Kesehatan.

f) Kelompok Pendidikan dan Olah Raga.

g) Kelompok Transportasi dan Komunikasi.

Kestabilan inflasi merupakan prasarat bagi pertumbuhan ekonomi dan pada akhirnya akan memberikan manfaat bagi kesejahteraan rakyat. Inflasi yang tidak stabil akan menciptakan ketidakpastian bagi pelaku ekonomi untuk mengambil keputusan berusaha. Pengalaman empiris membutktikan inflasi yang tidak stabil akan menyulitkan masyarakat untuk berkonsumsi dan investasi, sehingga pada akhirnya akan menurunkan pertumbuhan ekonomi.

Inflasi di Indonesia pada umumnya disebabkan oleh naiknya harga-harga bahan makanan, seperti sayur mayur, daging sapi, ayam, dan sebagainya. Dibandingkan dengan negara-negara sesama ASEAN, tingkat inflasi Indonesia paling tinggi. Menurut Badan Pusat Statistik (BPS) pada tahun 2015 inflasi di Indonesia sebesar 7,18\%; Malaysia sebesar 3\%; Philipina sebesar 3,3\%; Singapura sebesar 1,5\%; Thailand sebesar 1,8\%; Vietnam sebesar 4,0\%. (BPS,2015).

1. Teori Inflasi (Sukirno, 2006)

a) Teori Kuantitas Uang

Teori ini menjelaskan bahwa inflasi terjadi karena jumlah uang yang beredar meningkat tidak seimbang dengan barang yang tersedia. Landasan pokok teori ini ialah

Dimana:

$$
\mathbf{M V}=\mathbf{P T}
$$

$\mathrm{M}=$ Suplai uang dalam perekonomian.

$\mathrm{V}=$ Kecepatan sirkulasi uang dalam perekonomian

$\mathrm{P}=$ Harga rata-rata semua transaksi dalam perekonomian

$\mathrm{T}=$ Jumlah transaksi dalam perekonomian dalam periode khusus

$\mathrm{PT}=$ Ukuran jumlah pengeluaran dalam perekonomian

$\mathrm{MV}=$ merupakan jumlah uang yang digunakan

Kedua ruas persamaan ini harus identik dalam nilai uang yang digunakan. Kadang-kadang $\mathrm{T}$ ditulis Q yakni output perekonomian, sehingga $\mathrm{MV}=\mathrm{PQ}$ yakni total pengeluaran nasional dalam suatu periode dan ini sama dengan PDB (Produk Domestik Bruto) 
b) Teori Keynes

Teori Keynes mengenai inflasi berdasarkan teori makronya. Menurut teori Keynes, inflasi terjadi karena suatu masyarakat ingin berbelanja di luar batas kemampuan ekonominya. Keadaan ini ditandai dengan permintaan masyarakat akan barang-barang melebihi jumlah barang-barang yang tersedia, sehingga menimbulkan "inflation gap". Selama inflation gap tetap ada, selama itupula proses inflasi akan berkelanjutan. Keynes berpendapat bahwa kenaikan harga bukan hanya disebabkan oleh banyaknya uang yang beredar, tetapi disebabkan oleh kenaikan ongkos produksi.

c) Teori Strukturalis

Teori Strukturalis adalah teori inflasi jangka panjang, karena melihat sebab-sebab inflasi yang berasal dari kekakuan (infleksibilitas) struktur ekonomi suatu negara. Menurut teori ini ada dua ketegaran (kekakuan) utama dalam perekonomian negara sedang berkembang yang dapat me nimbulkan inflasi, yakni kekakuan suplai bahan makanan dan barang-barang ekspor.

2. Cara Mengatasi Inflasi

1) Dengan Kebijakan Moneter

a) Politik uang ketat, mengurangi jumlah uang yang beredar.

b) Kebijakan pasar terbuka, menjual surat-surat berharga.

c) Pembatasan kredit usaha.

2) Dengan Kebijakan Fiskal

a) Mengurangi pengeluaran pemerintah, melakukan penghematan.

b) Mengurangi hutang-hutang luar negeri, jangan terlalu banyak impor.

c) Menaikan pajak.

3. Dampak Inflasi terhadap Perekonomian

1) Terhambatnya pertumbuhan ekonomi negara karena berkurangnya investasi serta berkurangnya minat menabung akibat inflasi.

2) Masyarakat yang berpenghasilan rendah tidak dapat menjangkau harga barang, karena harga barang meningkat terus.

3) Jika ada kebijakan untuk mengurangi inflasi, maka akan terjadi pengangguran karena pemerintah berusaha menekan harga.

4) Masyarakat cenderung untuk mengimpor barang daripada menyimpan uang.

5) Nilai mata uang turun, karena adanya kenaikan harga barang.

\section{Indeks Pembangunan Manusia (IPM)}

Pengukuran pembangunan manusia pertama kali diperkenalkan oleh United Nation Development Program (UNDP) pada tahun 1990. United Nation Development Program (UNDP) memperkenalkan sebuah gagasan baru dalam pengukuran pembangunan manusia yang disebut sebagai Indeks Pembangunan 
Manusia (IPM). Sejak saat itu Indeks Pembangunan Manusia (IPM) dipublikasikan secara berkala dalam laporan tahunan Human Development Report (HDR). Indeks Pembangunan Manusia (IPM) menjelaskan bagaimana penduduk dapat mengakses hasil pembangunan dalam memperoleh pendapatan, kesehatan, pendidikan, dan sebagainya. (UNDP, 1990).

Menurut United Nation Development Program (UNDP), Indeks Pembangunan Manusia (IPM) mengukur capaian pembangunan manusia berbasis sejumlah komponen dasar kualitas hidup. Sebagai ukuran kualitas hidup, Indeks Pembangunan Manusia (IPM) dibangun melalui pendekatan tiga dimensi dasar. Dimensi dasar tersebut mencakup:

a. Umur panjang dan hidup sehat (a long and healthy life).

b. Pengetahuan (knowledge).

c. Standar hidup layak (decent standard of living).

Ketiga dimensi tersebut memiliki pengertian sangat luas karena terkait banyak faktor. Pada laporan pertamanya, United Nation Development Program (UNDP) mengukur dimensi kesehatan dengan menggunakan angka harapan hidup waktu lahir. Selanjutnya untuk mengukur dimensi pengetahuan digunakan angka melek huruf. Adapun untuk mengukur dimensi standar hidup layak digunakan indikator Produk Domestik Bruto (PDB) per kapita. (UNDP, 1990).

1. Manfaat Indeks Pembangunan Manusia (IPM)

Indeks Pembangunan Manusia (IPM) menjadi salah satu indikator penting dalam melihat sisi lain dari pembangunan. Manfaat penting dari Indeks Pembangunan Manusia (IPM) antara lain sebagai berikut :

a) Indeks Pembangunan Manusia (IPM) merupakan indikator penting untuk mengukur keberhasilan dalam upaya membangun kualitas hidup manusia (masyarakat/penduduk).

b) Indeks Pembangunan Manusia (IPM) dapat menentukan peringkat atau level pembangunan suatu wilayah/negara.

Di Indonesia Indeks Pembangunan Manusia (IPM) merupakan data strategis, karena selain sebagai ukuran kinerja pemerintah, Indeks Pembangunan Manusia (IPM) juga digunakan sebagai salah satu indikator penentuan Dana Alokasi Umum (DAU).

2. Konsep Pembangunan Indonesia

Manusia adalah kekayaan bangsa yang sesungguhnya. Tujuan utama dari pembangunan adalah menciptakan lingkungan yang memungkinkan bagi rakyatnya untuk menikmati umur panjang, sehat dan menjalankan kehidupan yang produktif. Hal ini tampaknya merupakan suatu kenyataan yang sederhana. Tetapi hal ini sering kali terlupakan oleh bebagai kesibukan jangka pendek untuk mengumpulkan harta dan uang.

Kalimat pembuka pada Human Development Report (HRD) pertama yang dipublikasikan oleh United Nation Development Program (UNDP) tahun 1990 secara jelas menekankan arti pentingnya pembangunan yang berpusat pada manusia yang menempatkan manusia sebagai tujuan akhir, dan bukan sebagai alat pembangunan. 
Mengutip isi Human Development Report (HRD) pertama tahun 1990, pembangunan manusia adalah suatu proses untuk memperbanyak pilihanpilihan yang dimiliki oleh manusia. Diantara banyak pilihan tersebut, pilihan yang terpenting adalah untuk berumur panjang dan sehat, untuk berilmu pengetahuan, dan untuk mempunyai akses terhadap sumber daya yang dibutuhkan agar dapat hidup secara layak. (UNDP, 1990).

Untuk menghindari kekeliruan dalam memakai konsep ini, perbedaan antara cara pandang pembangunan dengan pendekatan konvensional yang menekankan pertumbuhan ekonomi, pembentukan modal manusia, pembangunan sumber daya manusia, kesejahteraan rakyat, dan pemenuhan kebutuhan dasar perlu diperjelas. Konsep pembangunan manusia mempunyai cakupan yang lebih luas dari teori konvensional pembangunan ekonomi.

Model pertumbuhan ekonomi lebih menekankan pada peningkatan Produk Domestik Bruto (PDB) daripada memperbaiki kualitas hidup manusia. Pembangunan sumber daya manusia cenderung untuk memperlakukan manusia sebagai input dari proses produksi sebagai alat, bukan sebagai agen dari perubahan dalam proses pembangunan. (Todaro, 2003). Adapun pendekatan kebutuhan dasar terfokus pada penyediaan barang-barang dan jasa-jasa untuk kelompok masyarakat tertinggal, bukannya memperluas pilihan yang dimiliki manusia di segala bidang.

Pendekatan pembangunan manusia menggabungkan aspek produksi dan distribusi komoditas, serta peningkatan dan pemanfaatan kemampuan manusia. Pembangunan manusia melihat secara bersamaan semua isu dalam masyarakat, pertumbuhan ekonomi, perdagangan, ketenagakerjaan, kebebasan politik, maupun nilai-nilai kultural dari sudut pandang manusia. (Kuncoro, 2003).

\section{METODE PENELITIAN}

Data yang digunakan penelitian ini adalah data sekunder yang diperoleh dari Badan Pusat Statistik (BPS) dari tahun 2000 - 2015. Variabel operasional yang diperlukan dalam penelitian ini adalah inflasi dan Indeks Pembangunan Manusia (IPM) yaitu kesejahteraan. Metode analisis data yang digunakan adalah analisis kuantitatif, antara lain:

1. Analisis Koefisien Korelasi Sederhana. Analisis koefisien korelasi dilakukan untuk mengetahui hubungan variabel bebas $(\mathrm{X})$ yaitu Inflasi dengan variabel terikat (Y) yaitu Indeks Pembangunan Manusia (IPM). Rumus yang digunakan adalah sebagai berikut:

$$
r=\frac{n \sum X Y-\sum X \sum Y}{\sqrt{\left[n \sum X^{2}-\left(\sum X\right)^{2}\right]\left[n \sum Y^{2}-\left(\sum Y\right)^{2}\right]}}
$$


Nilai $r$ akan diinterpretasikan berdasarkan tabel dibawah ini.

Tabel 1.

Intepretasi Koefisien Korelasi

\begin{tabular}{cl}
\hline INTERVAL KOEFISIEN & TINGKAT HUBUNGAN \\
\hline $0,00-0,19$ & Sangat rendah \\
$0,20-0,39$ & Rendah \\
$0,40-0,59$ & Sedang \\
$0,60-0,79$ & Kuat \\
$0,08-1,00$ & Sangat kuat \\
\hline
\end{tabular}

2. Analisis Koefisien Determinasi. Analisis koefisien determinasi dilakukan untuk melihat kontribusi Inflasi terhadap Indeks Pembangunan Manusia (IPM). Rumus yang digunakan sebagai berikut:

$$
K D=r^{2} \times 100 \%
$$

3. Analisis Regresi Linear. Analisis regresi digunakan untuk melihat ketergantungan variabel tidak bebas pada variabel bebas. Dengan maksud untuk meramalkan nilai variabel tidak bebas. Persamaan Regresi Linier Sederhana:

$$
\mathrm{Y}=\mathrm{a}+\mathrm{bX}
$$

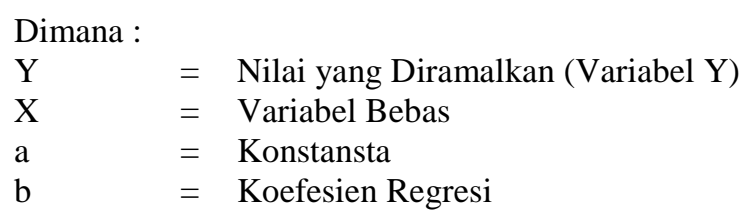

Menghitung nilai $\mathrm{b}$ dan a dengan rumus sebagai berikut:

$$
b=\frac{n\left(\sum X Y\right)-\sum X \sum Y}{n\left(\sum X^{2}\right)-\left(\sum X\right)^{2}} \text { dan } a=\frac{\left(\sum Y\right)\left(\sum X^{2}\right)-\left(\sum X\right)\left(\sum X Y\right)}{n\left(\sum X^{2}\right)-\left(\sum X\right)^{2}}
$$

4. Analisis Hipotesis.

Untuk mengetahui pengaruh Inflasi terhadap Indeks Pembangunan Manusia (IPM) digunakan uji $t$, dengan rumus sebagai berikut:

$$
t=\frac{r \sqrt{n-2}}{\sqrt{1-r^{2}}}
$$

Dengan kriteria penerimaan hipotesis sebagai berikut:

Ho diterima, jika $t_{\text {hitung }} \leq \mathrm{t}_{\text {tabel }}$

Ha diterima, jika $\mathrm{t}_{\text {hitung }} \geq \mathrm{t}_{\text {tabel }}$

5. Untuk mengetahui besarnya elastisitas Inflasi terhadap Indeks Pembangunan Manusia (IPM) digunakan rumus sebagai berikut: 


$$
\boldsymbol{e}=\left[\frac{\Delta Y}{\Delta X}\right]\left[\begin{array}{l}
\bar{X} \\
\overline{\bar{Y}}
\end{array}\right]
$$

Keterangan:

$e$ menunjukkan elastisitas $\mathrm{X}$ terhadap $\mathrm{Y}$

$e>1=$ elastis

$e<1=$ inelastis.

$e=1=$ unitary

$\Delta \mathrm{Y}=$ Perubahan $\mathrm{Y}$

$\Delta \mathrm{X}=$ Perubahan $\mathrm{X}$

$\bar{X}=$ Rata-rata $\mathrm{X}$

$\bar{Y}=$ Rata-rata $\mathrm{Y}$

\section{PEMBAHASAN}

\section{Data Penelitian}

Data penelitian yang diperoleh dari Badan Pusat Statistik tahun 20002015 disajikan dalam tabel berikut ini:

Tabel 2.

Data Inflasi dan Indeks Pembangunan Manusia (IPM)

Tahun 2000 - 2015

\begin{tabular}{ccc}
\hline Tahun & Inflasi & $\begin{array}{c}\text { Kesejahteraan Indeks } \\
\text { Pembanguan Manusia ( IPM) }\end{array}$ \\
\hline 2000 & 9,40 & 69,57 \\
2001 & 12,55 & 64,30 \\
2002 & 10,03 & 65,30 \\
2003 & 5,16 & 65,80 \\
2004 & 6,40 & 68,70 \\
2005 & 17,11 & 69,57 \\
2006 & 6,60 & 70,10 \\
2007 & 6,59 & 70,59 \\
2008 & 11,06 & 71,17 \\
2009 & 2,78 & 71,76 \\
2010 & 6,96 & 72,27 \\
2011 & 3,79 & 72,77 \\
2012 & 4,30 & 73,29 \\
2013 & 8,38 & 73,81 \\
2014 & 8,36 & 74,29 \\
2015 & 3,30 & 75,30 \\
\hline \multicolumn{2}{c}{ Sumber : BPS 2015}
\end{tabular}

\section{Analisis Data Penelitian}

Berdasarkan data pada Tabel 2 diperoleh nilai koefisien korelasi (r) sebesar $\mathbf{- 0 , 4 2}$. Hal ini menunjukan bahwa terdapat hubungan yang negatif antara Inflasi dengan Indeks Pembangunan Manusia (IPM) dengan katagori sedang. Kontribusi Inflasi terhadap Indeks Pembangunan Manusia (IPM) sebesar $\mathbf{1 7 , 6 4 \%}$ (koefisien determinasi) dan sisanya sebesar $82,36 \%$ adalah kontribusi faktor lain. Kontribusi inflasi ini kecil karena adanya kebijakan 
pemerintah memberikan bantuan kepada kepada masyarakat golongan ekonomi lemah.

Untuk mengetahui sejauh mana ketergantungan Indeks Pembangunan Manusia (IPM) pada Inflasi dilakukan analisis Regresi Linier Sederhana. Dari hasil analisis dengan menggunakan data pada tabel 2 didapat persamaan regresi linier sederhana, $\mathbf{Y}=\mathbf{7 3 , 3 3}-\mathbf{0 , 3 6 X}$. Persamaan regresi linier sederhana ini menunjukkan apabila Inflasi naik $1 \%$ maka Indeks Pembangunan Manusia (IPM) akan turun sebesar 0,36 \% dengan nilai konstanta sebesar 73,33. Dari perhitungan dengan regresi ini tampak juga pengaruh Inflasi terhadap Indeks Pembangunan Manusia (IPM) rendah $(0,36 \%$ tidak sampai $1 \%)$. Hal ini disebabkan karena adanya bantuan dari pemerintah kepada masyarakat.

Untuk mengetahui pengaruh Inflasi terhadap Indeks Pembangunan Manusia (IPM) dilakukan uji-t (uji statistik) sebagai berikut:

$$
t_{\text {hitung }}=\frac{r \sqrt{n-2}}{\sqrt{1-r^{2}}}=\frac{-0,42 \sqrt{16-2}}{\sqrt{1-0,1764}}=-1,73
$$

Hipotesis penelitian sebagai berikut:

$\mathrm{H}_{0}$ : Tidak terdapat pengaruh Inflasi terhadap Indeks Pembangunan Manusia (IPM)

$\mathrm{H}_{\mathrm{a}}$ : Terdapat pengaruh Inflasi terhadap Indeks Pembangunan Manusia (IPM)

Dengan $\alpha$ sebesar $5 \%$ dan $\mathrm{dk}(16-2=14)$ diperoleh nilai $\mathrm{t}_{\text {tabel }}$ sebesar 1,761. Dikarenakan nilai $\mathrm{t}_{\text {hitung }}<\mathrm{t}_{\text {tabel }}$ atau $-1,73<1,761$, maka $\mathrm{H}_{0}$ diterima dan Ha ditolak yang berarti tidak terdapat pengaruh yang signifikan antara Inflasi terhadap Indeks Pembangunan Manusia (IPM).

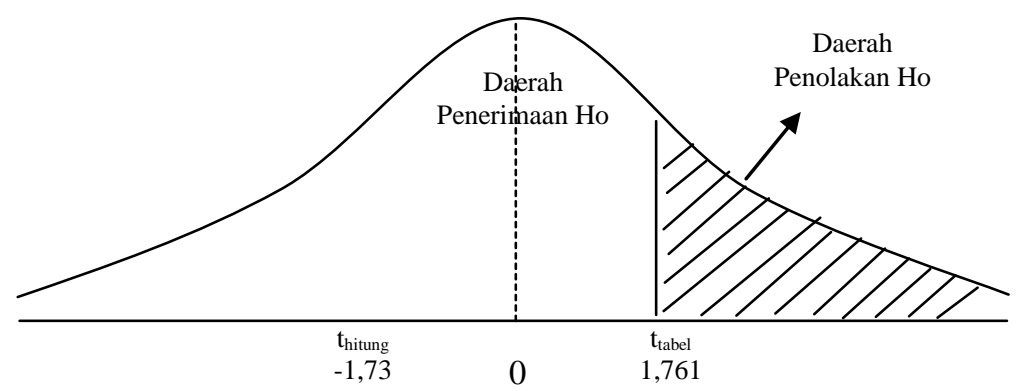

Gambar 1. Kurva Analisis Hipotesis 
Untuk mengetahui besarnya elastisitas Inflasi terhadap Indeks Pembangunan Manusia (IPM) digunakan rumus sebagai berikut:

$$
e=\left[\frac{\Delta Y}{\Delta X}\right]\left[\frac{\bar{X}}{\overline{\bar{Y}}}\right]=\left[\frac{0,38}{-0,41}\right]\left[\frac{7,67}{70,54}\right]=-0,10
$$

Harga mutlaknya $-0,10<1$. Ini berarti jika inflasi meningkat $1 \%$ maka indeks pembangunan manusia (IPM) akan turun kurang dari 1\%. Sehingga antara inflasi dan IPM tidak elastis atau inelastis.

\section{Pembahasan}

Seperti telah kita ketahui bahwa tingkat inflasi yang tinggi akan berpengaruh pada indeks pembangunan manusia (IPM). Dalam penelitian ini ternyata inflasi tidak mempunyai pengaruh yang signifikan terhadap indeks pembangunan manusia (IPM) dan tingkat elastisitasnya juga kecil.

Inflasi merupakan gejala ekonomi yang menghantui perekonomian setiap negara. Hal ini disebabkan karena dampaknya yang luas, seperti golongan masyarakat yang berpenghasilan tetap akan menderita (berkurang kesejahteraannya). Karena harga bahan baku menjadi meningkat maka pengusaha akan menderita juga. Pemerintah juga menemui kesulitan untuk meningkatkan pajak, karena tenaga kerja dan produsen sama-sama menderita dan menurun kesejahteraannya.

Beberapa hasil penelitian dari berbagai pakar di beberapa negara menunjukkan bahwa inflasi yang relatif rendah (lebih kecil dari dua digit atau dibawah $10 \%$ ) akan merangsang pertumbuhan ekonomi, seperti jika harga naik sedikit merangsang produsen untuk meningkatkan usaha, akan banyak tenaga kerja terserap, keuntungan pengusaha juga meningkat, akhirnya pemasukan pajak juga lancar dan meningkat, yang pada gilirannya akan meningkatkan pertumbuhan ekonomi.

Di akhir pemerintahan Orde Lama, yakni dekade tahun 1960-an inflasi rata-rata sampai 196,08\%, yakni paling parah, bahkan pada tahun 1969 inflasi tercatat $635,35 \%$. Untunglah pada awal pemerintahan Orde Baru tahun 1969 inflasi berhasil diturunkan hingga 9,89\% (BPS 2010). Keberhasilan penurunan inflasi ini berkat kebijakan moneter Orde Baru yang berhati-hati dalam mengendalikan uang yang beredar, serta memperhatikan kekuatan (daya beli) masyarakat akan barang-barang keperluan sehari-hari. Selain itu harga minyak terus disubsidi agar terhindar dari dampak harga dunia yang cenderung naik pada waktu era Orde Baru.

Di era pemerintahan sekarang ini inflasi dapat dikendalikan meskipun subsidi bahan bakar minyak dicabut. Keberanian pemerintah sekarang ini mencabut subsisdi minyak ditopang oleh harga minyak dunia yang turun dan stabil. Pada tahun 2015 tercatat oleh Badan Pusat Statistik (BPS) inflasi 3,3\%. Di Indonesia menurut para pakar ekonomi makro, inflasi dipicu oleh biaya produksi yang meningkat dan ongkos sektor angkutan yang naik akibat harga minyak yang naik. Hasil penelitian ini menunjukkan inflasi dalam era tahun 2000 - 2015 tidak berpengaruh pada indeks pembangunan 
manusia (IPM) dan elastisitas inflasi terhadap indeks pembangunan manusia (IPM) tidak elastis (inelastis). Hal ini disebabkan adanya kebijakan pemerintah untuk memberikan bantuan kepada masyarakat golongan ekonomi lemah atau miskin, seperti : operasi pasar untuk kebutuhan pokok, Bantuan Langsung Tunai (BLT), Kartu Indonesia Sehat, Kartu Indonesia Pintar.

\section{E. PENUTUP}

\section{Simpulan} berikut:

Berdasarkan hasil analisis data, maka dapat ditarik simpulan sebagai

a. Terdapat hubungan yang negatif antara inflasi dengan indeks pembangunan manusia (IPM) dengan katagori sedang yang ditunjukkan oleh nilai koefisien korelasi sebesar -0,42 dan kontribusi yang diberikan oleh inflasi kepada indeks pembangunan manusia (IPM) sebesar 17,64\% (koefisien determinasi).

b. Jika inflasi mengalami peningkatan sebesar $1 \%$, maka indeks pembangunan manusia (IPM) akan mengalami penurunan sebesar 0,36\% dengan nilai konstanta sebesar 73,33. Hal ini ditunjukkan oleh persamaan regresi linier $\mathrm{Y}=73,33-0,36 \mathrm{X}$.

c. Inflasi tidak mempunyai pengaruh yang signifikan terhadap indeks pembangunan manusia (IPM) dan elastisitas inflasi terhadap indeks pembangunan manusia (IPM) juga tidak elastis (inelastis).

\section{Saran}

a. Dikarenakan inflasi tidak mempunyai pengaruh yang signifikan terhadap indeks pembangunan manusia (IPM), maka pemerintah diharapkan tetap meneruskan kebijakan memberikan bantuan kepada masyarakat golongan ekonomi lemah atau miskin agar mereka dapat memenuhi kebutuhan hidupnya.

b. Untuk penelitian selanjutnya disarankan meneliti pengaruh inflasi terhadap tingkat kemiskinan di Indonesia. 
I.Pangesti, R. Susanto / Journal of Applied Business and Economics Vol. 5 No. 1 (Sept 2018) 70-81

\section{DAFTAR PUSTAKA}

Badan Pusat Statistik. (2015), Indeks Pembangunan Indonseia 2010-2015.

Kremer et al. (2009), Inflation and Growth: New Evidence from a Dynamic Panel Threshold Analysis. Discussion Paper, FUB School of Business and Economics.

Kuncoro, Mudrajad. (2003), Ekonomi Pembangunan: Teori, Masalah dan Kebijakan. (2nd ed.). Yogyakarta: UPP AMP YKPN.

Mankiw, Gregory. (2006), The Macroeconomist as a Scientist and an Engineer.

Sugiyono. (2012), Metodologi Penelitian Bisnis. Bandung : Alfabeta.

Sukirno, Sadono. (2006), Pengantar Teori Makro Ekonomi. Jakarta: Raja Grafindo Persada.

Sukirno, Sadono. (2006), Ekonomi Pembangunan (Edisi Kedua). Jakarta: Kencana.

Todaro, Michael, P. dan Stephen C. Smith. (2003), Pembangunan Ekonomi Di Dunia Ketiga, Edisi Kedelapan, Jakarta: Erlangga.

United Nation Development Program (UNDP). (1990). Human Development Report 1990. New York: Oxford University Press.

Wan, Usman. (2004), Metode Kuantitatif. Jakarta: Universitas Terbuka.

Wan, Usman. (2016), Sepuluh Langkah dalam Menulis Skripsi, Tesis, Disertasi. Pascasarjana Universitas Indonesia Program Studi Pengkajian Ketahanan Nasional. 